\title{
ANVERSO Y REVERSO DEL «QUIJOTISMO» EN EL SIGLO XVIII ESPAÑOL
}

\author{
Francisco Aguilar Piñal \\ C.S.I.C.
}

La fortuna de Cervantes está indisolublemente unida a la fortuna del Quijote. Cada generación histórica ha hecho del autor y de su genial novela espejo de sus propias convicciones y aspiraciones estéticas, morales y sociales. $Y$ es precisamente en el siglo XVIII cuando nacen las principales manifestaciones de esa fortuna: de un lado, el "cervantismo" como tarea investigadora, y de otro, el «quijotismo», en sus dos vertientes, como asimilación popular de una actitud quijotesca ante la vida.

Aunque, sin duda, el tema merece un estudio mucho más extenso, voy a presentar aquí un muestreo, que creo significativo, de las diferentes actitudes que los españoles de la llústración tomaron ante las aventuras del caballero andante, el cual, siendo personaje excelso del barroco, estuvo presente en las preocupaciones socio-culturales del siglo $\mathrm{XVIII,} \mathrm{con} \mathrm{una} \mathrm{vigencia} \mathrm{no} \mathrm{compartida} \mathrm{por} \mathrm{ningún} \mathrm{otro} \mathrm{personaje} \mathrm{litera-}$ rio.

Los testimonios se pueden multiplicar, pero me bastará con hacer re- 
ferencia a biógrafos, comentaristas y críticos, imitadores y continuadores, con alguna cala en la poesía popular. Podríamos señalar como el comienzo de este interés dieciochesco la edición del Quijote en Barcelona, el año 1704, en plena Guerra de Sucesión, después de treinta años transcurridos sin que la novela pasara por la imprenta. $O$ las publicaciones populares, adaptadas al gusto y necesidades del pueblo llano, de las obras cervantinas, como las realizadas en Sevilla por el impresor Antonio Hermosilla. Pero será más preciso decir que las aguas fueron removidas en 1732 cuando el presbítero y bibliotecario real Blas Antonio de Nasarre hace imprimir en Madrid, con la aprobación del académico Agustín de Montiano, el Quijote de Avellaneda, en donde sostiene que esta novela es superior a la de Cervantes. La idea no era nueva. La había expuesto el francés Lesage en su traducción parisina de 1704. Nasarre y Montiano, afrancesados hasta la médula, no dudan en aceptar la tesis del francés e introducirla como novedosa en España, consiguiendo convencer a otros literatos, como Torres Villarroel, que defiende el mismo criterio en la segunda edición de su obra El ermitaño y Torres, pero suscitando las iras de otros eruditos en esta primera polémica cervantina del XVIII.

Al año siguiente llega a la Corte, para trabajar al lado de Nasarre en la biblioteca real, el catedrático valenciano Gregorio Mayans y Siscar, el valor más sólido del humanismo crítico en el XVIII español. Mayans venía precedido ya de un bien ganado prestigio erudito, razón por la cual recibió un delicado encargo: redactar la vida de Cervantes para una edición del Quijote que se preparaba en Londres, con el fin de obsequiar a la familia real inglesa. Apasionado de la novela cervantina, Mayans aceptó el encargo, aun a sabiendas de que supondría el enfrentamiento con su inmediato superior en la biblioteca del Rey. Este es el punto de partida de una renovación total de los estudios cervantinos, en especial de la biografía del autor, montada hasta entonces sobre un cúmulo de errores, como se comprueba leyendo la edición de 1727 del Diccionario historico de Moreri.

Las investigaciones iniciadas por Mayans son el primer paso de los hallazgos documentales que se van sucediendo a partir de entonces: la partida de bautismo de Cervantes (1748), la de su fallecimiento (1749), la de su matrimonio (1755), el acta de redención del cautiverio de Argel, inserta en la biografía que escribió $D$. Vicente de los Ríos para la edición de la Real Academia Española (1780). Esta edición académica fue, como dice con cierta tristeza un comentarista, «el primer tributo de admiración de carácter oficial que rindió su patria al Príncipe de los ingenios 
españoles, cuando ya su nombre era famoso y su libro admirado en toda Europa».

Prescindo, sin embargo, de las investigaciones biográficas y de las polémicas, para centrar mi atención en el sentido y significado que tiene para los hombres del XVIII la actitud "quijotesca» del héroe cervantino. Sobre este eje fundamental han de girar todas las interpretaciones de la novela, que fue reeditada treinta y siete veces en España durante este siglo. Para los principales eruditos de la centuria, Cervantes es un gran escritor satírico, que destruye algo tan pernicioso a la sociedad como las fantasiosas novelas de caballerías. Según ellos, éste sería un quijotismo positivo, en tanto que moralizador y corrector social. Oigamos lo que dicen: Mayans habla de la eficacia de la medicina aplicada por Cervantes con su burla de los libros de caballerías, «pues purgó los ánimos de toda Europa de tan envejecida afición a semejantes libros tan pegajosos». $Y$ dice del Quijote que es «una sátira, la más feliz que hasta hoy se ha escrito" (1737). Torres Villarroel escribe que "no se puede inventar contra las necedades caballerescas invectiva más agria» (1738). Sarmiento afirma que Cervantes «hizo despreciables los libros de caballerías» (1772). Y Lampillas, que "desacreditó las historias fantásticas y ridículas de los antiguos libros de caballerías» (1778).

Sempere y Guarinos, al traducir las Reflexiones sobre el buen gusto de Muratori (1782), en donde se defiende la sátira como eficaz medio para reformar los abusos, no duda en añadir: «por este medio destruyó Cervantes el ridículo heroismo de los caballeros». El jesuita Juan Andrés, historiador de la literatura, escribe en parecidos términos: «La verdadera gloria de Don Quijote es el haber logrado el intento de quitar de las manos de todos los libros de caballerías, que por tantos siglos y con tanto perjuicio del buen gusto habían formado las delicias de la mayor parte de Europan (1783). Con mayor énfasis se pronuncia Forner: «Habianos venido de Francia el inepto gusto de los libros de caballerías, que tenian como en embeleso a la ociosidad del vulgo, ínfimo y supremo. Clama Vives contra el abuso; escúchale Cervantes; intenta la destrucción de tal peste; publica el Quijote y ahuyenta, como a las tinieblas la luz al despuntar el sol, aquella insípida e insensata caterva de caballeros, despedazadores de gigantes y conquistadores de reinos nunca oídos" (1786). La misma idea repite Pellicer, para quien el Quijote es «un Amadís de Gaula pintado a lo burlesco» (1797).

En la misma línea, pero ampliando el campo de la sátira, se manifiesta el biógrafo cervantino Vicente de los Ríos, indicando que «la moral de 
esta fábula no sólo es útil por los varios objetos que abraza, sino también por la discreción con que los reprehende, a medida del esfuerzo preciso para desarraigarlos del espíritu del vulgo. Como nuestro autor se proponía el verdadero objeto de la sátira justa, que es mejorar a los hombres, no se contentó con impugnar los vicios caballerescos, sino que, de paso, y según le venía la ocasión, reprehendió casi todos los defectos de las demás profesiones y estados» (1780).

Para los eruditos ilustrados, como se ve, Don Quijote era un personaje extravagante pero que servía admirablemente para el intento de destruir algo tan absurdo para la mentalidad neoclásica como las novelas de caballerías. Es la voz de la razón contra la sinrazón y fantasía inverosímil. Esta reacción admirativa pasa más allá del terreno de la crítica, dando lugar a imitaciones y continuaciones de la novela, con ese mismo espíritu demoledor, que ya no se concreta en las desaparecidas novelas de caballerías, sino en los más variados defectos sociales de la época. Así, el quijotismo dieciochesco es ya una actitud beligerante que se propone abatir los residuos barrocos de la vida y las costumbres, en nombre de la razón y del buen gusto. El escritor del XVIII que se siente animado por el espíritu de la sátira se cree un Cervantes redivivo, dispuesto a enderezar todos los entuertos de la sociedad que le rodea. Veamos algunos ejemplos.

Francisco de la Justicia y Cárdenas publica El Piscator de Don Quijote (1745) «para satirizar los andantes piscatores». El Padre Isla hace de su Fray Gerundio el Quijote de los predicadores (1758), pero en realidad es él mismo quien se siente Don Quijote, como afirma en carta a su hermana (1). Por su parte, el periódico madrileño titulado El bufón de la corte (1767) manifiesta su pretensión de ser «un Don Quijote del buen gusto», y otro periódico, El Censor (1785), se proclama a sí mismo «Don Quijote del mundo filosófico, procurando desfacer errores de todo género y enderezar entuertos $y$ sinrazones de toda especie».

Con el látigo de la sátira en la mano, salen también a denunciar defectos sociales, en aras de la mentalidad neoclásica: el sacerdote Donato de Arenzana, con su Don Quijote de la Manchuela (1767) en el que arremete contra los necios que pretenden seguir estudios académicos; Manuel del Pozo, que en su Quijote sainetero (1769) ridiculiza a los malos poetas que sientan plaza de moralizadores; Cadalso, que en Los erudi-

(1) Publicada en la Biblioteca de Autores Españoles, tomo XV, pág. 481. 
tos a la violeta (1772) critica la falsa erudición; Tomás de Iriarte, quien introduce a Cervantes en Los literatos en cuaresma (1773) con el objeto de censurar las comedias del día, «espejos de disparates, ejemplos de necedades e imágenes de lascivia»; Juan Beltrán y Colón, autor de La acción de gracias a Doña Paludesia (1780), que presenta como obra póstuma del Bachiller Sansón Carrasco, fustiga con violencia la vanidad de los literatos; Alonso Ribero y Larrea, con su Quijote de la Cantabria (1782) insiste en la sátira contra el afán nobiliario; el agustino fray Pedro Centeno hace salir al segundo Quijote, «alias el Escolástico» (1788) bajo el seudónimo de Eugenio Habela Patiño, para demoler la obsoleta filosofía escolástica; Moratín, en La derrota de los pedantes (1789) toma por modelo el Viaje del Parnaso para satirizar a los malos poetas; finalmente, Cándido María Trigueros (continuador de La Galatea) da vida al Quijote de los teatros (1802) para enderezar los vicios de la escena. Novela, pues, digna de imitación para los ilustrados, que sólo ven en el género novelesco su utilidad como sátira de costumbres.

También el teatro del XVIII ofrece algunos casos de obras inspiradas en la novela cervantina. Tal es el caso de El Alcides de la Mancha y famoso Don Quijote (1750) de Rafael Bustos Molina; Las bodas de Camacho (1784) de Meléndez Valdés; El amor hace milagros (1784) de Pedro Benito Gómeż Labrador; El Rutzvandscadt o Quijote trágico (1785) de José Pisón y Vargas; las Aventuras de Don Quijote y religión andantesca, manuscrito anónimo, sin fecha, sobre el pasaje de Lucinda y Dorotea (2).

Pero cuando la novela de Cervantes no puede colmar las aspiraciones satíricas del siglo, en algún tema determinado, aparecen las imitaciones y continuaciones, adaptadas a las nuevas tendencias ideológicas. Tal ocurre, por ejemplo, con el tema de la desigualdad social. Ahora ya no se ve el lado positivo de la sátira, sino el negativo de la vanidad quijotesca. Quijotismo será, entonces, la pretensión nobiliaria o de enriquecimiento burgués del estamento llano. Desear un ascenso en la escala social, sin méritos suficientes para ello, es para el ilustrado locura quijotesca, o mejor, sanchopancesca, como en los ejemplos que siguen. El desenlace es distinto, pero la consecuencia moral, es idéntica.

Una de las dos principales continuaciones del Quijote que se publican en el XVIII es debida a la pluma de Jacinto María Delgado, y apareció en

(2) V. Cotarelo, Imitaciones castellanas de/ Quijote. Madrid, 1900. 
1786 con el título de Adiciones a la historia del ingenioso Hidalgo Don - Quixote de la Mancha, en que se prosiguen los sucesos ocurridos a su escudero, el famoso Sancho Panza, escritas en arábigo por Cide Hamete Benengeli, y traducidas al castellano con las memorias de la vida de éste (3). Comienza esta novela mostrando la tristeza de Sancho, no tanto por su soledad tras la muerte de su señor, como por haber vuelto de nuevo.al cuidado de los puercos, recordando con nostalgia su efímero gobierno de la Insula Barataria. Compadecido el Cura de su comprensible y lastimoso estado de ánimo, interviene para que el Duque le llame otra vez a sus estados. En el capítulo XIII se ironiza de forma inmisericorde sobre la ascendencia de los Panzas, "casa gallega - dice - y una de las primeras familias; su fundador fue Roger-Lanza, que hizo fuertes hazañas en la guerra contra moros». En premio a sus servicios, el rey le otorgó la nobleza, en cuyo escudo de armas aparecian unos «bigotes en campo rojon. La actitud de los Duques ante la ingenua credulidad de Sancho no puede ser más cruel, al tiempo que se inserta en las críticas nobiliarias de la época. En la pomposa ceremonia de la investidura con el título de Barón, el otrora sencillo escudero hubo de jurar «defender que ninguno de su familia se dedique a arte $u$ oficio, por honesto que sea, prefiriendo que aumenten el número de holgazanes, vagabundos, inútiles en la República, aun cuando se mueran de hambre». Finaliza la vida del escarnecido y vanidoso rústico de una colosal indigestión, digno remate a la ridicula pretensión de encumbramiento social, cuya sola idea anatematiza el autor de esta durísima sátira.

Cinco años después aparece en Madrid otro libro: La moral del más famoso escudero Sancho Panza, con arreglo a la historia que del más hidalgo manchego Don Quixote de la Mancha escribió Cide Hamete Benengeli. Su autor, Pedro Gatell, que años antes había dado a luz otro libro titulado La moral de Don Quixote (1789), dice en el prólogo: «Mi empeño es que se desengañen muchos de los Quijotes y Sanchos del día, y que, lejos de imitar a aquellos dementes y fuera de juicio, los imiten cuerdos y ejemplares». El argumento se repite: Sancho vuelve a la casa de los Duques y al gobierno de su Insula, pero el desenlace es muy distinto, ya que el ingenuo aldeano termina desengañado de la nobleza y del gobierno, «entregándose de nuevo al primitivo destino de guardar cabras o trabajar en el campon. El autor concluye que la resolución de Sancho «es un modelo digno de que le imiten todos los que sirven». Es

(3) V. Cotarelo, "Otro imitador de Cervantes en el siglo XVIII", en Revista Contemporánea, 28 de febrero de 1899 . Reproducido en Estudios de historia literaria de España. Madrid, 1901, I, pp. 52-69. 
decir, la intención del novelista no es otra que la defensa a ultranza del orden social establecido: cada clase o estamento deberá mantenerse en su sitio, y la sociedad tendrá la obligación de frenar - ya sea por la sátira, ya por el desengaño - el afán nobiliario del tercer estado.

Es lo que, en ripiosos versos, define como «quijotismo» el poeta Juan Caldevila Bernaldo de Quirós:

Hablo del quijotismo,

o vanidad infame

de no vivir contento

con su destino nadie.

El español orgullo

- o vanidad se llame-

de querer ser más todos

$y$ todos igualarse...

la causa son y origen

de tantos holgazanes

$y$ vagos sin destino

que inundan los lugares.

De un menestral el hijo, que heredó de su padre un fondo que ha costado sudores mil y afanes, en vez, pues, de seguir su oficio y aplicarse, en gastar sólo piensa su herencia y sus caudales por parecerle indigno de un joven tan galante seguir el bajo oficio de pobres menestrales.

Un hidalgo de villa, vanidoso, ignorante, cuyo vínculo antiguo treinta pesos no vale, con sus veinte de censos, pensiones y gravámenes, embozado en su capa en las plazas y calles, todo el día se encuentra 


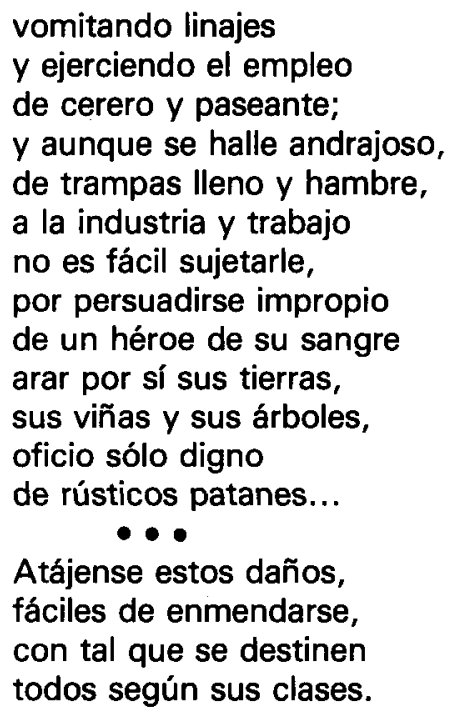

Un poco más allá va la interpretación grotesca de un anónimo poeta, que sólo ve en el héroe cervantino una veleidad altanera digna del mayor reproche. Sus versos aparecieron en el Diario de Valencia, el día 29 de diciembre de 1798, con el título El Don Quijote moderno. Entresecamos algunos versos significativos:

Entrar en una sala con desprecio

de cuantos hay en ella;

levantar la cabeza y toser recio...

Mandar con grave imperio

a quien tiene a sus órdenes humilde, intimarle muy serio

que no le pasará ni aun una tilde...

Ser egoísta fino, beber agua a la vista, y detrás vino;

ser veleta de torre,

que, según el aire, asi ella corre...

Si esto haces, Belisardo, no lo dudes, tendrás siempre la vara de virtudes, y llegarás de un bote a ser el más pintado Don Quijote. 
No terminan aqui, desde luego, las diversas interpretaciones que del personaje cervantino se hacen en el siglo XVIII. Su locura, por ejemplo, es destacada por el granadino Porcel, quien, al presentar su Juicio lunático en la Academia del Buen Gusto (1750) confiesa haberlo tomado por modelo con las siguientes palabras: «Dignamente se intituló [el propio Porcel] El Caballero de los Jabalies, como Don Quijote el de los Leones, pues en él hallamos el juicio desconcertado y la imaginación viciada, que en aquel manchego puso el señor Cervantes».

Por otra parte, el párroco madrileño y censor del consejo de Castilla, Juan de Aravaca, al aprobar las Memorias literarias de París, de Ignacio de Luzán, alaba a Cervantes "porque supo inventar felizmente una obra en que, además de la delicadeza y novedad de los pensamientos... acertó a juntar los caracteres más extraños que pudieran imaginarse, conservando en cada uno el genio, el modo, la locución y las demás circunstancias que le convienen, con tanta perfección y naturalidad que apenas habrá libro más conducente para formar el buen gusto sobre todo". La misma naturalidad, verosimilitud y unidad sicológica de los personajes son puestas de relieve por Cándido María Trigueros en una disertación, comparativa entre el Telémaco y el Quijote, que presenta en 1761 en la Real Academia Sevillana de Buenas Letras. Don Quijote - dice - "siempre que le tocan en su tecla desbarra de un mismo modo... y Sancho, ni aun cuando es elevado a Gobernador pierde su sandia sencillez; siempre tiene cuidado de que no se le olvide el idioma de los necios y el lenguaje que aprendió entre los terrones» (4). El mismo Cadalso, en sus Cartas marruecas, insinúa que, por debajo de la apariencia satírica, hay en el Quijote «un conjunto de materias profundas e importantes». Al finalizar el siglo, en 1797, aparece en el horizonte de la crítica un nuevo aspecto a destacar, que tiene mucho de interpretación romántica. Me refiero a la visión de Don Quijote como «el más discreto y virtuoso de los hombres», en frase de Quintana.

Hay, pues, un quijotismo de Cervantes como el gran novelista satírico, que entusiasma a los intelectuales ilustrados, empeñados en una tarea de reforma literaria y social. Pero hay también, en el reverso del concepto, un quijotismo de Don Quijote y Sancho, residuo censurable de pasadas hueras hidalguías que, a toda costa, se quiere eliminar de la nueva sociedad. Este quijotismo, con un significado muy diverso del que le dará un siglo más tárde Mesonero Romanos, estaria encarna-

(4) V. Francisco Aguilar Piñal, "Un comentario inédito del Quijote en el siglo XVIII», en Anales Cervantinos, VIII, 1959, pp. 307-319. 
do en el menestral aburguesado con aspiraciones nobiliarias. Esta última postura sería llevada a sus últimas consecuencias en el inédito Viage de Roberto Montgolfier al País de los Antípodas de la Nueva Zelanda. Fábula instructiva que tiene por objeto el destierro del Quijotismo. Esta curiosa novela "utópica», con la que el autor, Ramón Bonifaz y Quintano, «intenta imitar a Cervantes», fue rechazada por la censura de la Real Academia de la Historia en 1786 y creo que el original se ha perdido (5).

Fuera de España, en el nuevo siglo, Federico Schlegel descubre un Quijote romántico, que se convierte para los escritores alemanes del $\mathrm{XIX}$ en "corifeo del Romanticismo" y representante fiel de la filosofía idealista. «Don Quijote - ha dicho Friedrich Schürr - es un romántico que quiere resucitar un mundo ideal hundido y vivirlo dentro de sily, quien añade: "La parodia literaria de los libros de caballerias no es lo esencial de la novela... El quijotismo, como deseo de vivir un ideal literario $u$ otro en la realidad... procedía de una actitud fundamentalmente romántica del poeta mismo». (6) Actitud crítica que es compulsada y confirmada por los románticos franceses, desde Viardot, Mérimée o Gautier hasta Victor Hugo primero, y por los grandes maestros del realismo después (Stendhal, Balzac, Flaubert, etc.). (7) El propio Menéndez Pelayo, entre nosotros, afirma que lo que provoca la locura de Don Quijote es su «individualismo anárquico», que no es sino el aspecto negativo del quijotismo.

Sea como fuere, los siglos XVIII y XIX son asiduos lectores del Quijo$t e$, obra en la que cada individuo, según su ideología, encuentra alguna resonancia que le es propia. El reformador ilustrado verá en el hidalgo un debelador de fantasías y defectos sociales; el crítico neoclásico, la unidad sicológica del personaje, fiel a sí mismo y a sus profundas convicciones; el liberal romántico, un enamorado caballero y un paladín del idealismo. Aún no se había llegado a la uniformidad de la crítica ni a las profundas lecciones humanísticas de la gran parodia cervantina. Pero el camino estaba ya siendo desbrozado en el siglo XVIII, el gran siglo del Quijote. Parodia literaria-utopía social. Estos son los dos polos sobre los que bascula la crítica española ilustrada. Primer eslabón de una cadena de fervores incondicionales que, sin solución de continuidad, llega hasta nuestros días. (104).

(5) Se conserva el expediente en el Archivo Histórico Nacional, sec. Consejos, leg. 5552

(6) Friedrich Schürr, "Cervantes y el romanticismo", en Anales Cervantinos, I, 1951, p. 46.

(7) J.J.A. Bertrand, «Génesis de la concepción romántica de D. Quijote en Francia», en Anales Cervantinos, III, 1953, pp. 1-41 y IV, 1954, pp. 41-76. 